\title{
KEANEKARAGAMAN JENIS BURUNG DIURNAL DI HUTAN JAJAU KECAMATAN MENTEBAH KABUPATEN KAPUAS HULU KALIMANTAN BARAT
}

\author{
(Diurnal Bird Species Diversity in Jajau Forest, Mentebah District Kapuas Hulu \\ Regency, West Kalimantan)
}

\section{Tri Suhendra, Erianto, Hafiz Ardian}

Fakultas Kehutanan Universitas Tanjungpura Jalan Imam Bonjol, Pontianak 78124

E-mail: Endasylva@gmail.com

\begin{abstract}
Mentabah sub-district is one of the territories in Kapuas Hulu, the province of West Borneo. The width is about $781,26 \mathrm{~km}^{2}$ with enormous potential for biodiversity. One of them is Jajau forest. The local people called it Jajau Forest that also known as Kerangas forest. The purpose of this research is to collect data about the diversity of Diurnal species in Jajau Forest in Mentabah sub-district, Kapuas Hulu, the province of West borneo. IPA ((Index Point Abundance) is used in this research that placed purposively. The result of this research shows that there are 111 birds species could be indetified with 938 birds include 39 families. This research showh that the variety of birds in this are is so high, it is 4.4221 .
\end{abstract}

Keywords: diversity of birds, Jajau Forest, Mentebah District

\section{PENDAHULUAN}

Kecamatan Mentebah merupakan kecamatan yang ada di Kabupaten Kapuas Hulu. Kecamatan Mentebah memiliki luas wilayah 781,26 km² dengan delapan desa yang secara administrasi masuk dalam wilayah Kecamatan Mentebah, yaitu Desa Menaren, Desa Suka Maju, Desa Tangai Jaya, Desa Tekalong, Desa Nanga Mentebah, Desa Tanjung Intan, Desa Kepala Gurung dan Desa Tanjung. Hutan Jajau merupakan areal berhutan yang ada di wilayah Kecamatan Mentebah yang sering dimanfaatkan oleh masyarakat setempat. Hutan Jajau merupakan sebutan dari masyarakat lokal atau penduduk setempat yang tidak lain hutan ini merupakan hutan kerangas. Mengacu pada peta lampiran SK Menteri Kehutanan Republik Indonesia No: 733/MenhutII/2014 Tentang Kawasan Hutan dan Konservasi Perairan Provinsi Kalimantan
Barat, areal ini masuk kedalam areal penggunaan lainya (APL). Hutan kerangas (Heath Forest) merupakan salah satu tipe hutan penting di Indonesia yang tumbuh di atas tanah podsol, tanah pasir kuarsa yang sarang, miskin hara dan $\mathrm{pH}$ rendah (masam) (Hilwan, 1996). Secara umum, hutan kerangas tumbuh di daerah dataran rendah beriklim selalu basah tetapi mempunyai potensi besar salah satu diantaranya yaitu satwa burung yang ada di kawasan tersebut.

Tingginya keanekaragaman spesies burung di suatu wilayah didukung oleh tingginya keanekaragaman habitat, karena habitat bagi satwa liar secara umum berfungsi sebagai tempat untuk mencari makan, minum, istirahat, dan berkembang biak (Alikodra, 2002). Lingkungan yang berubah akan mengakibatkan perubahan kondisi ekologis yang ditandai dengan menurunnya potensi keanekaragaman 
hayati, khususnya satwa liar (Nandika, 2005). Selama proses evolusi dan perkembangan kehidupan berlangsung, burung selalu beradaptasi dengan berbagai faktor, baik kawasan biotik maupun abiotik. Hasil adaptasi ini mengakibatkan burung hadir atau menetap di suatu yang sesuai dengan kehidupannya dan tempat untuk kehidupannya tersebut secara keseluruhan disebut sebagai habitat (Rusmendro, 2004). Burung diurnal merupakan burung yang aktif disiang hari, sementara pada malam harinya tidur, selain burung ada beberapa satwa yang bersifat diurnal seperti golongan mamalia dan serangga. Tujuan penelitian ini yaitu mendata keanekaragaman jenis burung diurnal di areal Hutan Jajau Kecamatan Mentebah Kabupaten Kapuas Hulu Provinsi Kalimantan Barat. Hasil penelitian ini diharapkan dapat menyediakan data dan informasi ilmiah mengenai keanekaragaman jenis burung diurnal pada areal Hutan Jajau Kecamatan Mentebah Kabupaten Kapuas Hulu Provinsi Kalimantan Barat.

\section{METODE PENELITIAN}

\section{Pelaksanaan Penelitian}

Metode yang digunakan yaitu metode IPA (Index Point Abundance) yang ditempatkan secara purposive setelah itu dilanjutkan secara sistematik di dalam jalur pengamatan. Jalur pengamatan berjarak 100 meter antar jalur, dan panjang jalur pengamatan 750 meter. Jarak antar titik pengamtan 100 meter dengan radius 50 meter pada masing-masing titik pengamatan. Metode ini adalah pengabungan antara metode point count dan metode transek. Pelaksanaan pengamatan dilakukan pada 5 (lima) jalur pengamatan yang terpisah dengan 3 (tiga) kali pengulangan. Waktu pengamatan \pm 20 menit kemudian berjalan lagi dan berhenti dititik tertentu lalu mencatat perjumpaan terhadap burung. Radius pengamatan untuk setiap titik sejauh 50 meter dengan jarak tempuh sesuai dengan kondisi lapangan. Waktu pengamatan pagi pukul 05.00 - 09.00 WIB dan sore pukul 14.00 $17.30 \mathrm{WIB}$.

\section{Analisis data}

a. Indek dominasi burung

Untuk mengetahui jenis burung yang dominan ditentukan dengan menggunakan rumus berikut (Van Helvoort, 1981 dalam Syafrudin, 2011).

$$
\mathrm{DI}=\frac{n_{i}}{\boldsymbol{N}} \times 100 \%
$$

Keterangan :

$\mathrm{ID}=$ indeks dominasi suatu jenis burung

$\mathrm{ni}=$ Jumlah individu suatu jenis

$\mathrm{N}=$ Jumlah individu dari seluruh jenis

Kriteria dominasi:

$\mathrm{ID}=0-2 \%$ (jenis tidak dominan)

$\mathrm{ID}=2-5 \%$ (jenis sub dominan)

$\mathrm{ID}=>5 \%$ (jenis dominan)

b. Indeks Keanekaragaman Jenis (Diversity Index) dapat diketahui dengan rumus (Shannon, 1948; Karim dkk., 2016; Ahmad, 2017).

\section{$\mathbf{H}^{\prime}=-\mathbf{\Sigma}$ pi $\ln \mathbf{p i}$}

Keterangan :

$\mathrm{H}^{\prime}=$ Indeks keanekaragaman jenis

$\ln =$ Logaritma natural

pi $=$ Jumlah proporsi kelimpahan satwa spesies i

Kriteria nilai indeks keanekaragaman

Shannon-Wiener (H')

$\mathrm{H}^{\prime} \leq 1$ = Keanekaragaman jenis rendah

$1<\mathrm{H}^{\prime}<3=$ Keanekaragaman jenis sedang

$\mathrm{H}^{\prime} \geq 3$ = Keanekaragaman jenis tinggi 
c. Indeks Kemerataan Jenis (Evenes Index) dapat diketahui dengan menggunakan rumus (Daget, 1976; Adelina $d k k ., 2016)$.

$\mathbf{J}=-\Sigma$ pi $\ln (\mathbf{p i}) / \ln (\mathbf{S})$

Keterangan :

$\mathrm{J}=$ Indeks kemerataan

$\mathrm{S}=$ Jumlah spesies

Kriteria indeks kemerataan adalah sebagai berikut:

$0<\mathrm{J} \leq 0,5=$ Komunitas tertekan

$0,5<\mathrm{J} \leq 0,75=$ Komunitas labil

$0,75<\mathrm{J} \leq 1=$ Komunitas stabil

d. Indeks Kekayaan Jenis (Richness Index) dapat diketahui dengan rumus (Margalef, 1958; Setiawan $d k k ., 2006$ ).

$\mathrm{R}=\frac{S-1}{\ln N}$

Keterangan :

$\mathrm{R}=$ Indeks kekayaan jenis

$\mathrm{S}=$ Jumlah jenis yang teramati dalam suatu habitat

$\mathrm{N}=$ Jumlah individu (seluruh jenis) yang

teramati dalam suatu habitat

$\mathrm{Ln}=$ Logaritma natural

Kriteria nilai indeks kekayaan jenis apabila

$\mathrm{R} \leq 2,5=$ Kekayaan jenis rendah

$2,5<\mathrm{R}<4=$ Kekayaan jenis sedang

$\mathrm{R} \geq 4=$ Kekayaan jenis tinggi

\section{HASIL DAN PEMBAHASAN}

A. Jenis Burung Pada Seluruh Jalur Pengamatan

Komposisi Jenis burung diurnal yang ditemui di kawasan hutan jajau kecamatan mentebah kabupaten Kapuas hulu Kalimantan barat dapat dilihat pada Lampiran.

Hasil pengamatan pada jalur pertama menunjukkan bahwa jumlah burung yang ditemukan di areal penelitian ini sebanyak
72 spesies dari 32 family dengan jumlah individu sebanyak 242 individu yang didominasi oleh family pycnonotidae sebanyak 39 individu. Jalur dua menunjukkan bahwa jumlah spesies burung yang terdapat di areal penelitian ini sebanyak 52 spesies dari 26 family dengan jumlah individu sebanyak 146 individu yang didominasi family pellorneidae sebanyak 16 individu. Jalur tiga menunjukkan bahwa jumlah burung yang ditemukan di areal penelitian ini sebanyak 64 spesies dari 30 family dengan jumlah individu sebanyak 221 individu yang didominasi family pycnonotidae sebanyak 38 individu. Jalur empat menunjukkan bahwa jumlah burung yang ditemukan di areal penelitian ini sebanyak 48 spesies dari 23 family dengan jumlah individu sebanyak 129 individu yang didominasi family pycnonotidae sebanyak 21 individu, dan pada jalur lima menunjukkan bahwa jumlah burung yang ditemukan di areal penelitian ini sebanyak 59 spesies dari 27 family dengan jumlah individu sebanyak 200 individu yang didominasi family Pycnonotidae sebanyak 28 individu.

\section{B. Komposisi Jenis Burung diurnal pada Lokasi Penelitian}

Hasil pengamtan di lapangan yang berupa jumlah dan jenis burung pada setiap jalur pengamatan selanjutnya dilakukan analisis Data. Perhitungan analisis data yang dilakukan antara lain; indeks dominansi, indeks keanekaragaman jenis, indeks kemerataan jenis, indeks kekayaan jenis dan indeks kesamaan jenis. Hasil analisis data tersebut disajikan pada tabel 1. 
Tabel 1. Indek Dominasi, Indeks Keanekaragaman, Indeks Kemerataan, dan Indeks Kekayaan Burung Diurnal di Lokasi Penelitian (Dominance Index, Diversity Index, Evennes Index, and Richness Index Diurnal Bird in Research Lokation)

\begin{tabular}{ll}
\hline Indek dominasi (Van Helvoort, 1981) & 0.0141 \\
Indeks Keanekaragaman Jenis (Diversity Index) & 4.4221 \\
Indeks Kemerataan Jenis (Evenes Index) & 0.9390 \\
Indeks Kekayaan Jenis (Richness Index) & 308.2630 \\
Indeks Kesamaan Jenis & $60.77 \%$ \\
\hline
\end{tabular}

Berdasarkan Tabel 2, indeks dominasi menunjukan angka berjumlah 0.0141 berarti tidak ada jenis burung yang mendominasi. Menurut (Van Helvoort, 1981 dalam Syafrudin, 2011). Kriteria dominasi: $\mathrm{DI}=0-2 \%$ (jenis tidak dominan) $\mathrm{DI}=2-5 \%$ (jenis sub dominan) $\mathrm{DI}=>5 \%$ (jenis dominan). Indeks keanekaragaman pada seluruh jalur berjumlah 4,4221 angka ini menunjukan bahwa pada lokasi penelitian memiliki keanekragaman yang sangat tinggi. Menurut (Shanon - Wiener dalam Ferianita 2007), kisaran keanekaragaman jenis $(\bar{H})$ antara 1-3. Kisaran nilai $\bar{H}<1$ berarti keanekaragaman rendah, jika $1<$ $\bar{H}<3$ berarti keanekaragaman sedang dan jika $\bar{H}>3$ berarti keanekaragaman tinggi.

Indeks kemerataan jenis (Evenes Index) menunjukan angka berjumlah 0.9390 berati kondisi penyebaran jenis burung stabil. Menurut Indeks Kemerataan Jenis (Evenes Index) dapat diketahui dengan menggunakan rumus (Daget, 1976; Adelina $d k k$., 2016). Kriteria indeks kemerataan adalah sebagai berikut: $0<\mathrm{J} \leq$ $0,5=$ Komunitas tertekan , dan $0,5<\mathrm{J} \leq$ $0,75=$ Komunitas labil, sedangkan $0,75<$ $\mathrm{J} \leq 1=$ Komunitas stabil. Indeks kekayaan jenis menunjukan angka berjumlah 308.2630 artinya kekayaan jenis burung yang berada di areal penelitian tinggi. Menurut Indeks Kekayaan Jenis (Richness Index) dapat diketahui dengan rumus (Margalef, 1958; Setiawan $d k k .$, 2006).

Kriteria nilai indeks kekayaan jenis apabila :, $\mathrm{R} \leq 2,5=$ Kekayaan jenis rendah, 2,5 < $\mathrm{R}<4=$ Kekayaan jenis sedang, $\mathrm{R} \geq 4=$ Kekayaan jenis tinggi.

\section{KESIMPULAN}

Berdasartkan hasil penelitian ini menunjukan bahwa angka keanekaragaman jenis burung diurnal pada kawasan hutan jajau kecamatan mentebah kabupaten Kapuas hulu provinsi kalimantan barat memiliki keanekaragaman yang sangat tinggi dengan jumlah nilai $\bar{H}=4,4221$.

\section{SARAN}

1. Perlu perhatian khusus dari pihak pemerintah terhadap kegiatan peti yang ada disekitar lokasi penelitian.

2. Perlu dibuat peraturan desa terkait pengelolan hutan jajau supaya lebih terjaga kelestariannya

3. Perlu dlakukan kajian lebih lanjut seperti kajian Etnobotani, kajian etnozologi guna mempertahankan keberataan hutan jajau tersebut.

\section{UCAPAN TERIMA KASIH}

Penulisan mengucapkan terima kasih pada pengelola Hutan Jajau Sehingga 
penulis dapat melakukan penelitian untuk penyusunan skripsi sebagai tugas akhir di Fakultas Kehutanan Universitas Tanjungpura

\section{DAFTAR PUSTAKA}

Alikodra HS. 2002. Pengelolaan Satwa Liar jilid 1. Departemen Pendidikan Dan Kebudayaan Direktorat Jendral Pendidikan Tinggi Riset Antar Universitas Ilmu Hayati Institut Pertanian Bogor.

Daget J. 1976. Les Modeles Mathematiques En Ecologie. Masson, Paris. 172 hlm.

Hilwan I. 1996. Ekologi dan Diversity Ekosistem Hutan Tropika Indonesia. Bogor: Pusat Pengkajian Keanekaragaman Hayati, Institut Pertanian Bogor.

MacKinnon J, Phillipps K, Van Balen B. 1998. Seri Panduan Lapangan Burung-burung di Sumatera, Jawa, Bali dan Kalimantan. Bogor: Birdlife InternationalIndonesia Program - Pusat Penelitian dan Pengembangan Biologi LIPI.

Margalef R. 1958. Temporal Succession and Spatial Heterogeneity in Phytoplankton In A. A. BuzzatiTraverso(ed), Perspective in Marine Biology.Univ. California Press. 323-349.

Nandika D. 2005. Hutan Bagi Ketahanan Nasional. Universitas Muhamadiyah Surakarta.

Odum EP. 1983. Basic Ecology, Sauders College Publishing - Holt Saunders, Japan. 1993. Dasar-dasar Ekologi Edisi Ketiga. Yogyakarta: University Gadjah Mada Press.Rombang

Rudyanto. 1999. Daerah Penting Bagi Burung Jawa dan Bali.
PKA/Birdlife InternationalIndonesia Programme. Bogor.

Rusmendro H. 2009. Perbandingan Keanekaragaman Burung Pada Pagi Dan Sore Hari di Empat Tipe Habitat Diwilayah Pengandaran, Jawa Barat. Jurnal Vis Vitalis Fakultas Biologi Universitas Nasional, Jakarta.

SK.733/Menhut-II/2014. tentang Kawasan Hutan dan Konservasi Perairan Provinsi Kalimantan Barat.

Sawitri R, Mukhtar AS, dan Iskandar S. 2010. Status Konservasi Mamalia dan Burung di Taman Nasional Merbabu. Jurnal Penelitian Hutan Dan Konservasi Alam.

Sawitri R dan Iskandar S. 2012. Keragaman Jenis Burung Di Taman Nasional Kepulauan Wakatobi Dan Taman Nasional Kepulauan Seribu. Jurnal Peneitian Hutan Dan Konservasi Alam. Vol. 9 No. 2 : 175-187, 2012.

Shannon CE. 1948. A mathematical theory of communication. J. The Bell System Technical. (27) : 379-423.

Syafrudin D. 2011. Keanekaragaman Jenis Burung Pada Beberapa Tipe Habitat di Tambling Wildlife Nature Conservation (TWNC), Taman Nasional Bukit Barisan Selatan Lampung. Skripsi. Departemen Konservasi Sumberdaya Hutan dan Ekowisata Fakultas Kehutanan IPB. Bogor.

Whitmore TC. 1984. Tropical Rainforest of the Far East. 2nd ed. Oxford: Clarendon Press.

Welty JC. 1982. The Life Of Bird. 3nd Edition. Saunders College Publishing. Philadelpphia: Philadelphia. 


\section{Lampiran}

Tabel 2. Jenis-jenis Burung Diurnal yang Ditemukan pada Seluruh Jalur Penelitian (Diurnal Birds Species that Found in All Line Research)

\begin{tabular}{|c|c|c|c|c|c|c|c|}
\hline No & Family & Nama latin & ni & CITES & IUCN & P.106 & End \\
\hline 1 & Accipitridae & Haliastur indus & 4 & II & $\mathrm{LC}$ & P.106 & \\
\hline 2 & Accipitridae & Spilornis cheela & 4 & II & $\mathrm{LC}$ & P.106 & \\
\hline 3 & Aegithinidae & Aegithina tiphia & 6 & & $\mathrm{LC}$ & & \\
\hline 4 & Alcedinidae & Pelargopsis capensis & 2 & & $\mathrm{LC}$ & & \\
\hline 5 & Alcedinidae & Ceyx erithaca & 11 & & $\mathrm{LC}$ & & \\
\hline 6 & Apodidae & Collocalia esculenta & 8 & & $\mathrm{LC}$ & & \\
\hline 7 & Artamidae & Artamus leucorynchus & 4 & & $\mathrm{LC}$ & & \\
\hline 8 & Bucerotidae & Anthracoceros malayanus & 14 & II & NT & P.106 & \\
\hline 9 & Calyptomenidae & Calyptomena viridis & 9 & & NT & & \\
\hline 10 & Campephagidae & Hemipus hirundinaceus & 10 & & $\mathrm{LC}$ & & \\
\hline 11 & Campephagidae & Coracina fimbriata & 12 & & $\mathrm{LC}$ & & \\
\hline 12 & Campephagidae & Pericrocotus flammeus & 2 & & $\mathrm{LC}$ & & \\
\hline 13 & Caprimulgidae & Eurostopodus temminckii & 1 & & $\mathrm{LC}$ & & \\
\hline 14 & Chloropseidae & Chloropsis cyanopogon & 20 & & NT & P.106 & \\
\hline 15 & Cisticolidae & Orthotomus atrogularis & 7 & & $\mathrm{LC}$ & & \\
\hline 16 & Cisticolidae & Orthotomus ruficeps & 6 & & $\mathrm{LC}$ & & \\
\hline 17 & Cisticolidae & Orthotomus sericeus & 6 & & $\mathrm{LC}$ & & \\
\hline 18 & Cisticolidae & Prinia flaviventris & 6 & & $\mathrm{LC}$ & & \\
\hline 19 & Columbidae & Chalcophaps indica & 3 & & $\mathrm{LC}$ & & \\
\hline 20 & Columbidae & Macropygia emiliana & 3 & & $\mathrm{LC}$ & & \\
\hline 21 & Corvidae & Corvus enca & 3 & & $\mathrm{LC}$ & & \\
\hline 22 & Corvidae & Platysmurus aterrimus & 19 & & $\mathrm{LC}$ & & B \\
\hline 23 & Cuculidae & Centropus bengalensis & 1 & & $\mathrm{LC}$ & & \\
\hline 24 & Cuculidae & Centropus sinensis & 12 & & $\mathrm{LC}$ & & \\
\hline 25 & Cuculidae & $\begin{array}{l}\text { Phaenicophaeus malayanus } \\
\text { Phaenicophaeus }\end{array}$ & 1 & & $\mathrm{LC}$ & & \\
\hline 26 & Cuculidae & chlorophaeus & 14 & & $\mathrm{LC}$ & & \\
\hline 27 & Cuculidae & Cuculus micropterus & 6 & & $\mathrm{LC}$ & & \\
\hline 28 & Cuculidae & Surniculus lugubris & 2 & & $\mathrm{LC}$ & & \\
\hline 29 & Cuculidae & Cacomantis merulinus & 16 & & $\mathrm{LC}$ & & \\
\hline 30 & Cuculidae & Cacomantis sonneratii & 15 & & $\mathrm{LC}$ & & \\
\hline 31 & Dicaeidae & Dicaeum trigonostigma & 1 & & $\mathrm{LC}$ & & \\
\hline 32 & Dicaeidae & Dicaeum cruentatum & 1 & & $\mathrm{LC}$ & & \\
\hline 33 & Dicruridae & Dicrurus paradiseus & 17 & & $\mathrm{LC}$ & & \\
\hline 34 & Estrildidae & Lonchura fuscans & 9 & & $\mathrm{LC}$ & & B \\
\hline 35 & Eurylaimidae & Eurylaimus ochromalus & 22 & & NT & & \\
\hline 36 & Falconidae & Microhierax fringillarius & 9 & II & $\mathrm{LC}$ & P.106 & \\
\hline 37 & Megalaimidae & Psilopogon australis & 22 & & $\mathrm{LC}$ & & \\
\hline 38 & Megalaimidae & Psilopogon rafflesii & 24 & & NT & P.106 & \\
\hline 39 & Meropidae & Nyctyornis amictus & 20 & & $\mathrm{LC}$ & & \\
\hline 40 & Muscicapidae & Copsychus saularis & 2 & & $\mathrm{LC}$ & & \\
\hline 41 & Muscicapidae & Cyornis superbus & 1 & & $\mathrm{LC}$ & & $\mathrm{B}$ \\
\hline 42 & Nectariniidae & Anthreptes singalensis & 2 & & $\mathrm{LC}$ & & \\
\hline 43 & Nectariniidae & Anthreptes rhodolaemus & 8 & & NT & P.106 & \\
\hline 44 & Nectariniidae & Arachnothera & 7 & & $\mathrm{LC}$ & & \\
\hline
\end{tabular}




\begin{tabular}{|c|c|c|c|c|c|c|c|}
\hline No & Family & Nama latin & ni & CITES & IUCN & P.106 & End \\
\hline & & hypogrammica & & & & & \\
\hline 45 & Nectariniidae & Aethopyga siparaja & 12 & & $\mathrm{LC}$ & P.106 & \\
\hline 46 & Nectariniidae & Arachnothera longirostra & 23 & & $\mathrm{LC}$ & & \\
\hline 47 & Pellorneidae & Trichastoma rostratum & 5 & & NT & & \\
\hline 48 & Pellorneidae & Trichastoma bicolor & 16 & & $\mathrm{LC}$ & & \\
\hline 49 & Picidae & Meiglyptes tristis & 4 & & EN & & \\
\hline 50 & Picidae & Hemicircus concretus & 4 & & $\mathrm{LC}$ & & \\
\hline 51 & Picidae & Dryocopus javensis & 6 & & $\mathrm{LC}$ & & \\
\hline 52 & Picidae & Mulleripicus pulverulentus & 14 & & VU & P.106 & \\
\hline 53 & Picidae & Micropternus brachyurus & 14 & & $\mathrm{LC}$ & & \\
\hline 54 & Picidae & Chrysophlegma miniaceum & 9 & & $\mathrm{LC}$ & & \\
\hline 55 & Picidae & Sasia abnormis & 10 & & $\mathrm{LC}$ & & \\
\hline 56 & Pittidae & Pitta sordida & 2 & & $\mathrm{LC}$ & P.106 & \\
\hline 57 & Psittacidae & Loriculus galgulus & 11 & II & $\mathrm{LC}$ & P.106 & \\
\hline 58 & Pycnonotidae & Pycnonotus atriceps & 17 & & $\mathrm{LC}$ & & \\
\hline 59 & Pycnonotidae & Euptilotus eutilotus & 20 & & NT & & \\
\hline 60 & Pycnonotidae & Microtarsus melanoleucos & 13 & & NT & & \\
\hline 61 & Pycnonotidae & Pycnonotus plumosus & 9 & & $\mathrm{LC}$ & & \\
\hline 62 & Pycnonotidae & Pycnonotus goiavier & 8 & & $\mathrm{LC}$ & & \\
\hline 63 & Pycnonotidae & Pycnonotus simplex & 15 & & $\mathrm{LC}$ & & \\
\hline 64 & Pycnonotidae & $\begin{array}{l}\text { Pycnonotus } \\
\text { erythropthalmos }\end{array}$ & 15 & & $\mathrm{LC}$ & & \\
\hline 65 & Pycnonotidae & Pycnonotus brunneus & 25 & & $\mathrm{LC}$ & & \\
\hline 66 & Rhipiduridae & Rhipidura javanica & 8 & & $\mathrm{LC}$ & P.106 & \\
\hline 67 & Sturnidae & Gracula religiosa & 18 & II & $\mathrm{LC}$ & P.106 & \\
\hline 68 & Timaliidae & Macronous bornensis & 10 & & $\mathrm{LC}$ & & \\
\hline 69 & Timaliidae & Macronous ptilosus & 13 & & NT & & \\
\hline 70 & Timaliidae & Stachyris nigricollis & 10 & & NT & & \\
\hline 71 & Timaliidae & Cyanoderma erythropterum & 9 & & $\mathrm{LC}$ & & \\
\hline 72 & Vangidae & Philentoma pyrhoptera & 7 & & $\mathrm{LC}$ & & \\
\hline 73 & Alcedinidae & Lacedo melanops & 11 & & $\mathrm{LC}$ & & B \\
\hline 74 & Bucerotidae & Buceros rhinoceros & 2 & II & NT & P.106 & \\
\hline 75 & Bucerotidae & Anorrhinus galeritus & 3 & II & NT & P.106 & \\
\hline 76 & Columbidae & Ducula aenea & 4 & & $\mathrm{LC}$ & & \\
\hline 77 & Irenidae & Irena puella & 6 & & $\mathrm{LC}$ & & \\
\hline 78 & Megalaimidae & Calorhamphus fuliginosus & 2 & & $\mathrm{LC}$ & P.106 & B \\
\hline 79 & Monarchidae & Hypothymis azurea & 13 & & $\mathrm{LC}$ & & \\
\hline 80 & Monarchidae & Terpsiphone paradisi & 13 & & $\mathrm{LC}$ & & \\
\hline 81 & Muscicapidae & Cyornis turcosus & 3 & & NT & & \\
\hline 82 & Muscicapidae & Rhinomyias umbratilis & 21 & & NT & & \\
\hline 83 & Pellorneidae & Malacopteron magnum & 19 & & NT & & \\
\hline 84 & Pellorneidae & Malacopteron albogulare & 11 & & NT & & \\
\hline 85 & Pellorneidae & Malacopteron cinereum & 12 & & $\mathrm{LC}$ & & \\
\hline 86 & Picidae & Blythipicus rubiginosus & 3 & & $\mathrm{LC}$ & & \\
\hline 87 & Psittacidae & Psittacula longicauda & 9 & II & VU & P.106 & \\
\hline 88 & Pycnonotidae & Setornis criniger & 1 & & VU & P.106 & \\
\hline 89 & Timaliidae & Stachyris maculata & 17 & & NT & & \\
\hline 90 & Trogonidae & Harpactes kasumba & 4 & & NT & P.106 & \\
\hline 91 & Trogonidae & Harpactes diardii & 9 & & NT & P.106 & \\
\hline 92 & Trogonidae & Harpactes orrhophaeus & 10 & & NT & P.106 & \\
\hline
\end{tabular}


JURNAL HUTAN LESTARI (2020)

Vol. 8 (4): 730 - 737

\begin{tabular}{|c|c|c|c|c|c|c|c|}
\hline No & Family & Nama latin & ni & CITES & IUCN & P.106 & End \\
\hline 93 & Turdidae & Copsychus pyrropygus & 11 & & NT & & \\
\hline 94 & Alcedinidae & Alcedo meninting & 1 & & $\mathrm{LC}$ & & \\
\hline 95 & Columbidae & Treron olax & 10 & & $\mathrm{LC}$ & & \\
\hline 96 & Cuculidae & Rhopodytes diardi & 2 & & NT & & \\
\hline 97 & Hemiprocnidae & Hemiprocne comata & 4 & & $\mathrm{LC}$ & & \\
\hline 98 & Muscicapidae & Muscicapa sibirica & 2 & & $\mathrm{LC}$ & & M \\
\hline 99 & Nectariniidae & Leptocoma sperata & 5 & & $\mathrm{LC}$ & & \\
\hline 100 & Pellorneidae & Malacopteron affine & 2 & & NT & & \\
\hline 101 & Phasianidae & Melanoperdix nigra & 1 & & VU & & \\
\hline 102 & Pycnonotidae & Iole olivacea & 6 & & NT & & \\
\hline 103 & Pycnonotidae & Tricholestes criniger & 7 & & $\mathrm{LC}$ & & \\
\hline 104 & Cuculidae & $\begin{array}{l}\text { Chrysococcyx } \\
\text { xanthorhynchus }\end{array}$ & 1 & & $\mathrm{LC}$ & & \\
\hline 105 & Dicaeidae & Prionochilus thoracicus & 1 & & NT & & \\
\hline 106 & Picidae & Meiglyptes tukki & 3 & & NT & & \\
\hline 107 & Pittidae & Erythropitta granatina & 5 & & NT & P.106 & \\
\hline 108 & Dicaeidae & Prionochilus maculatus & 1 & & $\mathrm{LC}$ & & \\
\hline 109 & Nectariniidae & Arachnothera robusta & 1 & & $\mathrm{LC}$ & & \\
\hline 110 & Oriolidae & Oriolus xanthonotus & 1 & & NT & & \\
\hline 111 & Picidae & Reinwardtipicus validus & 2 & & $\mathrm{LC}$ & & \\
\hline
\end{tabular}

